\title{
Paloma Ortiz-de-Urbina
}

\section{UN «BAYREUTH ESPAÑOL» PARA 1913: WAGNERIANOS DE MADRID Y BARCELONA EN UN PROYECTO COMÚN}

\section{Primeras asociaciones wagnerianas en España}

La obra de Wagner provoca en España, desde finales del siglo XIX, un profundo impacto en la sociedad, desatando apasionados y estimulantes debates en la prensa de la época y documentándose su huella no sólo en la música, sino también en otros campos artísticos como la literatura, la pintura o la escultura. Esta primera recepción wagneriana en España centra su principal actividad en Barcelona y Madrid, alcanzándose su punto álgido en torno a 1913, es decir, hace ahora cien años.

A pesar de que la huella wagneriana se manifiesta de muy diferente manera en dichas ciudades, las asociaciones wagnerianas que se crean en ambas se unen en 1911 en un fascinante proyecto común, hoy en día inimaginable, ejemplo paradigmático del entusiasmo vivido en España en torno a la obra de Richard Wagner: la construcción de un teatro wagneriano en Zaragoza, en lo alto de una montaña, junto al Monasterio de Piedra, con cabida para unas dos mil personas, en el que pudiera representarse la última obra de Wagner, el Bühnenweihfestspiel o festival escénico sacro, Parsifal, cuyo plazo de protección iba a expirar en toda Europa el 1 de enero de 1914.

Las cartas inéditas encontradas en el Fons Pena de la Biblioteca de Catalunya ${ }^{1}$ permiten reconstruir esta iniciativa ideada por el musicógrafo, crítico musical y fundador de la Associació Wagneriana de Barcelona Joaquim Pena y secundada, con ferviente entusiasmo, por los wagnerianos madrileños.

La Associació Wagneriana catalana fue creada el 19 de octubre de 1901, contando entre sus miembros a personajes de la intelectualidad catalana del momento tan prestigiosos como Antoni Ribera, Salvador Vilaregut, Lluís Suñé o Gerónimo Zanné. La Asociación Wagneriana de
1 El intercambio epistolar original entre las asociaciones wagnerianas de Madrid y Barcelona fue encontrado en 2003 en el Fons Pena de la Biblioteca de Catalunya y transcrito por vez primera en los Anexos de la tesis doctoral de la autora del presente artículo: P. ORTIZ-DEURBINA, La recepción de la obra de Richard Wagner en Madrid (1900-1914), junio 2003, Madrid, Universidad Complutense de Madrid. http://biblioteca. ucm.es/tesis/ghi/ucm-t26883. pdf [última consulta: 01-082013], pp. 574-593. 
2 Associació Wagneriana, Estatuts de la Associació Wagneriana reformats en la Junta General de 1 de Juliol del any 1902, Barcelona, 1902.

3 Vid. Paloma ORTIZ-DE-URBINA, Richard Wagner en España: La Asociación Wagneriana de Madrid (1911-1915), Monografías Humanidades, vol. 18, Servicio de Publicaciones de la Universidad de Alcalá, Madrid, 2007.

4 La correspondencia inédita fue encontrada en 2003, en cajas sin inventariar, en el Fons Pena de la Biblioteca de Catalunya.

5 Conrado del Campo fue miembro de la Asociación Wagneriana de Madrid desde el 31 de marzo de 1912 hastael 30 de junio de 1913, tal y como se documenta en las Listas de Socios de dicha Asociación.
Madrid fue creada diez años más tarde, a raíz del estreno de Tristán e Isolda en el Teatro Real de Madrid, el 31 de marzo de 1911, presidida por el Duque de Alba y formada por un amplio mosaico de la burguesía intelectualizada madrileña que reunía tanto a músicos (como Conrado del Campo, Arturo Saco del Valle o Enrique Fernández Arbós) como a escritores (Salvador de Madariaga), pintores (Aureliano Beruete, Rogelio de Egusquiza), médicos (Gregorio Marañón) o arquitectos (Miguel Otamendi). La tardía creación de la Asociación madrileña fue suplida con un nutrido número de socios. Si al año de su fundación, la Associació Wagneriana de Barcelona contaba con 251 socios, $^{2}$ su homónima madrileña contaba en marzo de 1912, transcurrido un año de su creación, con 1.747 asociados que, en junio de 1913, llegarían a 2.016 miembros. ${ }^{3}$

Cuatro meses después de la creación de la Asociación Wagneriana madrileña, el 4 de julio de 1911, el secretario de la misma, Manuel de Cendra, envía a Joaquim Pena, presidente de la Associació Wagneriana de Barcelona, una carta en la que le comunica la feliz noticia. Desde ese momento, ambas asociaciones mantendrán una intensa relación que se desprende de su intercambio epistolar ${ }^{4}$ entre el 4 de julio de 1911 y el 1 de julio de 1912.

\section{Contacto epistolar entre Madrid y Barcelona}

Manuel de Cendra comienza de este modo, el 4 de julio de 1911, la relación epistolar entre ambas asociaciones wagnerianas:

Mucho tiempo hace que tenía intención de dirigirme a $\mathrm{Vd}$. para darle cuenta de la constitución en Madrid de la Asociación Wagneriana que, tras no pequeña lucha, he organizado, teniendo la inmensa satisfacción de verla ya constituida con una pujanza extraordinaria y un gran entusiasmo por parte de los 1.550 socios con que hoy contamos, cada vez más entusiastas y defensores de la causa Wagneriana en sus dos manifestaciones literaria y musical.

Esta primera carta hace referencia, a continuación, a la visita que el compositor madrileño Conrado del Campo, miembro de la Asociación Wagneriana de Madrid, ${ }^{5}$ hizo a Joaquim Pena durante su estancia con la Orquesta Sinfónica en Barcelona. En la entrevista que mantuvieron ambos, quedó patente el interés de Pena por la Asociación madrileña. Por esta razón, Cendra envía el citado escrito, comunicándole todos los proyectos que existen para el invierno, adjuntando con este fin la circular informativa del 30 de junio, que daba a conocer las gestiones realizadas desde su 
fundación, así como las relativas a la programación de obras wagnerianas en el Teatro Real, la colaboración de Marcelino Menéndez y Pelayo con una conferencia sobre Die Meistersinger von Nürnberg y los planes de contratación del director de orquesta Hans Richter al frente de la Orquesta Sinfónica de Madrid. Tras resumir dichos proyectos, Cendra celebra la labor de la Associació catalana y hace referencia a aspectos económicos, reflejando ya cierta inquietud al respecto:

[...] haremos cuanto esté a nuestro alcance y bolsillo, pues no es ésta la menor dificultad que se nos presenta al tener una cuota mensual tan pequeña, como es la de 2 ptas, que se viene satisfaciendo.

Esta Asociación, identificada con la de Vds., no tiene otro deseo que adherirse a ella, empezando por aplaudir la meritísima labor por $V d s$. realizada, especialmente en la publicación de los poemas, labor interesantísima y de mucha importancia, que estamos nosotros empezando a realizar.

Para finalizar, Cendra solicita a la Associació Wagneriana de BarceIona el envío de las traducciones realizadas por los miembros de su Asociación, así como sus Estatutos, asegurando su pago a vuelta de correo y adjuntando los Estatutos de la Asociación Madrileña. Joaquim Pena responde inmediatamente a esta primera carta, agradeciendo los elogios, adjuntándole todas sus publicaciones y felicitando con total apoyo a su «ilustre compañera madrileña».6

\section{El proyecto de Piedra}

Como ya indicaba Alfonsina Janés en 1974, "a comienzos de 1912 lanzose en Barcelona una idea grandiosa para ensalzar la figura de Richard Wagner. Parece ser que la iniciativa partió de Joaquim Pena, pero fue el tenor [Francisco] Viñas quien la dio a conocer». ${ }^{7}$ A través del hallazgo de la correspondencia mantenida entre ambas entidades, sabemos ahora que dicho proyecto fue mucho más lejos de lo que se creía hasta ahora y fueron también muchos más los resortes que se tocaron para tratar de lograr el objetivo propuesto.

Efectivamente, la siguiente carta que intercambian las asociaciones wagnerianas madrileña y barcelonesa corresponde a la de la Asociación madrileña y está fechada el 12 de enero de 1912. En ella, su secretario hace por primera vez alusión al proyecto de Piedra:

Nuestro compatriota, el eminente tenor Sr. Viñas, me ha dado cuenta particularmente del grandioso proyecto que $\mathrm{Vds}$. tienen y que nosotros aplaudimos
6 Vid. Respuesta a la carta del 4 de julio de 1911.

7 Alfonsina JanÉs, La obra de Richard Wagner en Barcelona, tesis doctoral dirigida por Antoni Comas, Universidad de Barcelona, Barcelona, 1974, pp. 140-141. 
8 El Orfeó Català, dirigido por Lluís Millet, y gracias a la colaboración entre las asociaciones wagnerianas de Madrid y Barcelona, iba a actuar en el Teatro Real el 21 y 23 de abril de 1912.

9 Se trata de un borrador manuscrito que no incluye la fecha exacta, sino sólo febrero 1912. sin reservas, respecto a la próxima representación en España del sublime Parsifal.

De tan hermosa idea he dado cuenta a la Directiva de esta Asociación y todos, unánimemente, han prodigado su aplauso a este proyecto, que aprobamos en todas sus partes, dispuestos a colaborar con $V d s$. en todo lo que nuestras fuerzas permitan, deseando tener en Mayo una reunión en el Monasterio de Piedra, como Vds. proponen, y antes de esa época en Madrid, si lleva Vd. a la práctica su proyectado viaje a esta corte, según indicación hecha por el Sr. Viñas.

Joaquim Pena pensó en un principio aprovechar la visita del Orfeó Català 8 a la capital para entrevistarse con sus compañeros madrileños, pero no llegó finalmente a realizar su proyectada visita, por lo que la reunión quedó aplazada, para realizarse más tarde en el Monasterio de Piedra. Cendra pone ya de manifiesto en su carta su preocupación por la premura del tiempo. Era necesario coordinarse rápidamente, pues la idea de Joaquim Pena era la de celebrar, antes del estreno en 1914 del Parsifal, el centenario de Wagner en 1913, por lo que Cendra advierte:

[...] hay que tener presente que, aunque la representación se haya de celebrar en Junio de 1913, sólo queda año y medio, tiempo nada más que suficiente, tal vez escaso, para organizar tanto como es preciso llevar a la práctica venciendo los innumerables obstáculos que se han de encontrar en empresa de tanta magnitud, sobre todo para la formación de la Sociedad que construya el teatro, único medio posible de poder llevar a la escena este maravilloso drama.

El presidente de la Asociación Wagneriana madrileña da, sin embargo, su absoluto apoyo al proyecto y, en nombre de la Junta Directiva, expresa su "adhesión más incondicional», para lo que su Asociación, tal y como se demostrará a continuación, se muestra dispuesta «a colaborar en él [...] en la seguridad de no escatimar sacrificio alguno de orden económico e intelectual, uniendo todas nuestras fuerzas al feliz resultado de tan hermoso pensamiento». A continuación, Cendra solicita de Pena que le envíe «algo de lo que hayan pensado para dar cuerpo a esta idea, en su parte prosaica y material, que si bien es la más ingrata a tratar, desgraciadamente en cuestiones de arte, es en la que siempre estrellamos todos». Cendra se refiere al proyecto de Sociedad por acciones, «que aporte el capital necesario para tan grande obra».

La reacción de la Associació al escrito madrileño es rápida y la respuesta, extensísima. En la carta de febrero de $1912,{ }^{9}$ Joaquim Pena agradece largamente el entusiasmo con que su proyecto ha sido ya recogido en Madrid a través del mensaje oral de Francisco Viñas y ruega a la Asocia- 
ción Wagneriana madrileña que «se digne a aceptar el testimonio de mi franca amistad, al par que entusiasta admiración por la labor en pro de nuestra causa común, que con tanto éxito viene realizando esa magnífica Asociación Wagneriana». Menciona también que, junto a la carta, realiza «en un rollo separado» el envío certificado del proyecto de bases, aprobado por el Consejo Directivo de la Associació catalana y en el que, a lo largo de 13 puntos, expone la idea en líneas generales.

\section{La cuestión económica}

Joaquim Pena decide entonces en su carta ir directamente al meollo de la cuestión, comenzando por resaltar el aspecto económico:

El caballo de batalla será, sin duda, como Vd. ha visto bien desde un principio, el aspecto económico. Dado que forzosamente ha de ser cuestión de construir un teatro y dotarlo de tantos y tan complicados accesorios como exige su objetivo, el capital que para ello se requiere representa una suma muy respetable. ¿Podremos llegar a reunirla? Ahí está el problema, pero creo que no tiene nada de particular ni difícil intentarlo, guardándonos de dar un paso en firme hasta tener asegurado en buena parte el éxito de la suscripción, para evitarnos un ridículo fracaso.

Joaquim Pena parece tener muy clara la idea de cómo conseguir dicha suma: "Es cuestión de pulsar al instante la opinión en nuestros dominios respectivos y ver cómo responde». Es, sin embargo, consciente de la dificultad de un proyecto de tal magnitud y trata de evitar reincidir en un excesivo entusiasmo, que en otras ocasiones le produjo no pocos problemas, relatando así a Manuel de Cendra este resumen de su experiencia al frente de la Associació, que demuestra las dificultades que tuvo, desde un principio, para reunir una suficiente cantidad de socios y de costear los gastos producidos por las ediciones de las partituras y traducciones wagnerianas:

Llevo doce años tirando del carro, luchando constantemente y sacrificando tiempo y dinero para cosechar burlas y disgustos al principio, bien que después haya venido el conocimiento tardío pero franco y general, acompañado de un cúmulo de desmesuradas alabanzas, inútiles y hasta contraproducentes con apoyo material escaso. En la época de mayor apogeo, cuando prodigábamos las sesiones y conciertos, no llegamos a 400 socios; después, cuando estudiadas detenidamente todas las obras de Wagner y sin elementos para crear el teatro wagneriano que soñábamos, nos convertimos exclusivamente en sociedad editorial, hemos quedado constituyendo un núcleo de un centenar, 
con otro centenar que desde fuera nos ayuda en la edición de las partituras. Pero ¡si supiera $\mathrm{Vd}$. Ia lucha que nos cuesta cada vez colocar el resto de tan costosas ediciones!

Si a pesar de la experiencia vivida, la Associació catalana decide seguir adelante con el ambicioso proyecto, ello se debe precisamente a la existencia de la Asociación Wagneriana de Madrid:

Por todo ello, jamás hubiera pasado por mi mente una empresa tan arriesgada como la que proyectamos sin la creación de la entidad de Vds.

Al tener noticia de su existencia, pronto se me ocurrió que debíamos unirnos si queríamos celebrar el Centenario de una manera digna, sin las mogigangas [mojigangas] propias de casos análogos. Con la plétora de vida, con el entusiasmo que $V$ ds. traen y con el temperamento más desprendido que les caracteriza, creo que tenemos bastante ganado.

Joaquim Pena piensa que Madrid sería la ciudad que más capital podría aportar al proyecto. Bilbao podría quizá también ayudarles y Barcelona se sentiría quizá ahora animada a hacerlo, gracias a la reciente creación de la Asociación Wagneriana madrileña:

Para que salgamos adelante, es preciso que mi consocio Madrid, es decir, los pudientes de toda España que ahí tienen su residencia, carguen con buena parte del empréstito. Bilbao puede también hacer bastante, y en cuanto a Barcelona, yo he de poner alma y vida en remover hasta las piedras para ver si esta vez siquiera, por la trascendencia de la cosa y por la misma emulación de Vds., nuestras clases mercantiles, que son aquí los verdaderos potentados, se dignan a ayudarnos y nos evitan el ridículo.

\section{Propuestas de actuación}

Tras disculparse por la sinceridad en la inmediatez de sus juicios, propone medidas concretas para conseguir el objetivo perseguido:

Este es mi parecer, sin ambages ni rodeos, como sastre que conoce el paño, y por eso me apresuro a exponérselo francamente, para fijar bien el terreno que pisamos.

Es preciso, en consecuencia, lanzar bien la cosa. Meter en esa Junta organizadora, lo más numerosa posible, unos cuantos nombres de gente joven que arrastra, y jalearlo de lo lindo en la prensa. Y así, despertando la emulación y estimulando la vanidad, podremos hacer llegar a muchos a donde no conseguiría llevarlos el amor al arte. 
Más adelante, llega incluso a acariciar la idea de ser subvencionados por el Estado:

Si pudiéramos llegar a hacer contribuir al Estado, y si las clases altas nos patrocinaran de veras, creo que no habría que desmayar, para llegar a ver con nuestros proyectos abiertos lo que hoy también no es más que un sueño.

El secretario de la Associació Wagneriana catalana está convencido del éxito posterior del proyecto si éste pudiera ponerse en pie, justificándose de antemano en caso contrario:

Si la cosa arrancara, no hay duda que luego el éxito de los festivales puede darse por descontado. Y si no arranca, podremos siempre los organizadores tener la conciencia tranquila de que intentamos honrar la memoria del Genio, de la manera más digna y que, si se perdió, no fue por culpa nuestra.

Pena insiste en el aspecto no cerrado del proyecto, mostrándose flexible a cuantos cambios o añadidos propusiera la Asociación madrileña para este fin:

Repito que mi exposición del plan no es más que un proyecto, que no tengo criterio cerrado en ningún extremo del mismo y que, por tanto, así en el fondo como en la forma, a su superior criterio e inteligencia me remito, en la seguridad de que con las modificaciones y adiciones con que sabrán enriquecerla van a dejar la cosa perfectamente viable. Por eso no he querido fijar detalles, ni pretender por un momento imponer normas de acción a esa junta organizadora que debe ser la soberana absoluta.

\section{¿En qué idioma ha de cantarse Wagner?}

Únicamente en un aspecto, el que corresponde al lenguaje, considera necesario Joaquim Pena expresar su opinión. Y ésta resulta realmente interesante, pues refleja la preocupación latente en aquella época respecto al idioma en el que debían ser cantadas las óperas de Wagner. Como se refirió anteriormente, la excelente acogida y, sobre todo, la duradera y profunda asimilación de Richard Wagner en Cataluña se debió, fundamentalmente, a la labor realizada por los traductores. Joaquim Pena, Antoni Ribera, Geroni Zanné, Xavier Viura, Salvador Vilaregut, Joan Maragall, Josep Lleonart y Anna d'Ax: ${ }^{10}$ todos ellos tradujeron la obra de Wagner al catalán y todos ellos realizaron traducciones adaptadas a la música, es decir, traducciones para ser cantadas. La Associació editaba las traduc-
10 Para un análisis de las traducciones realizadas al catalán, muy concretamente de «Die Walküre», puede consultarse la tesis doctoral de Ana María BuJ I CAsanova, Les traduccions de Wagner al català: "La Walquiria», dirigida por Alfonsina Janés y Mireia Calvet. Dept. Filologia Anglesa i Alemanya, Universidad de Barcelona, 2007. Para el análisis de las traducciones wagnerianas al castellano. Vid. Paloma ORTIZ-DE-URBINA, "La traducción musical dentro del proceso receptor: Richard Wagner en España», en Actas del II Congreso Internacional AIETI. Universidad Pontificia de Comillas, Madrid, 2005, pp. 1188-1206. 
11 José Borrel Vidal, Sesenta años de música (18761936). Impresiones y comentarios de un viejo aficionado, prólogo de Conrado del Campo, Madrid, Dossat, 1945, p. 142.

12 Gaspar Gómez dE LA SERNA, Gracias y desgracias del Teatro Real de Madrid, Madrid, 1976, p. 64. ciones porque, en su tarea divulgadora del músico alemán, sabía que traducciones así eran necesarias para despertar en los cantantes el deseo de interpretar a Wagner. Las traducciones al catalán fueron recibidas por la prensa catalana de principios de siglo con absoluto júbilo y fueron, probablemente, responsables en gran parte del creciente interés, no sólo por Wagner, sino por la cultura de los países germanófonos en Cataluña. Joaquim Pena pensaba por ello que, cantadas ahora en castellano, las óperas alemanas contribuirían a una mayor difusión y posterior asentamiento de la obra de Wagner en España.

Se había llegado además, en aquel momento, a una situación realmente curiosa respecto al idioma en que eran cantadas las óperas wagnerianas, llegando a extremos inimaginables hoy en día. José Borrell relata al respecto: «en el reparto de las obras de Wagner alternaban artistas italianos con alemanes, con lo que resultaban audiciones bilingües, cosa no muy correcta ni conveniente, pero a la que tuvimos que acostumbrarnos a la fuerza, y hasta se dio el caso de que llegaron a ser trilingües, como en las representaciones en que intervenía Rousselière, que cantaba en francés». ${ }^{11}$ Éste fue el caso del estreno de Parsifal el 1 de enero de 1914 cantando, como señala Gómez de la Serna, cada intérprete en su idioma materno: «en francés el tenor Rousselière, en alemán la soprano Guszalevicz y en italiano los demás». ${ }^{12}$

Joaquim Pena desea luchar contra la costumbre de cantar en idiomas que el público no entiende, instaurando el hábito de representar a Wagner en español, para hacer su música accesible y popularizar su obra en España:

Sólo en un punto sí me ha parecido necesario precisar concretamente, y es en la cuestión del lenguaje. La gran incomprensión de las obras de Wagner por parte de muchos wagnerianos inclusive, estriba en la falta de atención al drama, suplida por un exceso de atención a la música, fomentada por las continuas representaciones en lengua extraña. Pues bien, creo que esta vez hay que poner la primera piedra, como la hemos puesto ya nosotros en el Liceo; hay que barrer a marchas forzadas la ignominia de la representación en italiano y no es lógico tampoco abrir la puerta al alemán, ni a pretexto de admirar interpretaciones de grandes artistas. El descomunal relato de Gurnemanz y la terrible lamentación de Amfortas no pueden menos de resultar una solemne lata a todo aquel que no siga palabra por palabra lo que dicen.

Para el presidente de la Associació Wagneriana catalana es, además, indispensable que las obras de Wagner se respeten en su longitud y no se corten en ningún lugar: 
Hay que tener además en cuenta que sólo el primer acto dura dos horas, y espero que no consentirán Vds. que se corte un solo compás, pues éste es mi otro caballo de batalla. Por eso es que hago hincapié tan sólo en este punto.

Ante los posibles problemas que podrían surgir por la implantación del castellano en la interpretación de las obras de Wagner, Pena se muestra seguro del éxito, recordando como él consiguió hacer cantar en catalán, con éxito, a la célebre soprano wagneriana Lina Pasini Vitale:

A esto nos objetarán sin duda: ¿y los artistas?, ¿y la traducción? Que cubran la suscripción y que no se preocupen por el resto, que todo lo demás saldrá. Me empeñé en hacer cantar en catalán a la Pasini Vitale, y todo el mundo quedó sorprendido al oír lo que hubiera creído siempre imposible. Conozco a muchos cantantes italianos que hablan el español más que suficientemente bien para poder echar mano de ellos.

Al ser competencia de la Asociación madrileña la traducción al casteIlano de la obra wagneriana, Pena, en su calidad de traductor, añade sensatos consejos e incluso ofrece su ayuda desde Barcelona:

En cuanto a la traducción castellana, a Vds. toca decidir. Permítanme sólo un consejo: mucho cuidado con las grandes firmas, los literatos eminentes, pues por el afán de crear, son los que acostumbran a desfigurar más el original. Y si nadie se veía con fuerzas, también aquí intentaríamos sacar adelante la empresa.

Por otra parte, la Associació ya se había puesto a trabajar en el proyecto, contactando con la familia del propietario del Monasterio de Piedra, donde se pensaba erigir el teatro:

Otra de las cuestiones perentorias es la de tratar con el propietario. Yo me he adelantado, comenzando ya los trabajos, pues como no ignorarán se trata de un paisano nuestro, y aunque se pase gran parte del tiempo en Calatayud y cuente ya 88 años, sus más próximos allegados están aquí y con ellos estamos ya gestionando para que le convenzan.

Se trata del escritor Juan Federico Muntadas Jornet, que había heredado de su padre este monasterio, realizando en él importantes reformas. La Associació contactará fundamentalmente con su hijo Ramón, pues el padre se encontraba ya enfermo, y fallecería ese mismo año, en el otoño de 1912. 
Por estas cartas sabemos también de la relación amistosa entre Joaquim Pena y miembros de la Asociación Wagneriana madrileña, como muestra la despedida de ésta, en la que hace mención a sus «entrañables amigos» Conrado del Campo, Félix y José Borrell.

\section{Audiencia con el rey Alfonso XIII}

A esta extensísima carta responde José María Marañón, pues Manuel de Cendra se encontraba ausente en ese momento, asumiendo Marañón, en su calidad de vocal de la Asociación, las funciones de secretario. En un breve escrito fechado el 19 de marzo de 1912, éste comunica a la Associació haber dado lectura, el día 4 de marzo, en Junta Extraordinaria, del proyecto en cuestión. Informa también de la intención de visitar, junto con Francisco Viñas, al mismo rey Alfonso XIII, con objeto de pedirle ayuda para la consecución del proyecto: «Tenemos pedida una audiencia al Rey, para cuando regrese de Lisboa el amigo Viñas».

El 1 de abril de 1912, Manuel de Cendra vuelve a escribir, tras su ausencia, una respuesta más oficial a la Associació Wagneriana catalana. Cendra había convocado a su regreso, el 20 de marzo, otra Junta Extraordinaria para el día 29 de marzo, por lo que transmite a Joaquim Pena lo aprobado en ésta:

1. ${ }^{\circ}$ Solicitar a S. M. el Rey, una audiencia para el día 19 del actual, en cuya fecha estará en Madrid el Sr. Viñas de paso para su excursión artística de Murcia, y con él acudir a Palacio una comisión de esta Wagneriana, que exponga a S. M. el proyecto, demandando su reapoyo [sic], en la forma más práctica que pueda conseguirse.

2. Nombrar una comisión que acuda a reunirse con la de Vds. en el Monasterio de Piedra, en la fecha de Mayo o Junio que ambas entidades convengan, estudiando sobre el terreno, con el entusiasmo peculiar en nosotros, el modo de dar forma al proyecto y cambiar pareceres e impresiones que seguramente serán los mismos, pues idéntico amor nos hermana; y

3. ${ }^{\circ}$ Comunicar el pensamiento que tenemos a todas aquellas personas que por su influencia, posición social, amor al divino arte o dinero factible, nos sirvan en su día y conozcan ya la idea grande que nos mueve y reúne, prestándola su apoyo, que por pequeño que cada cual nos otorgue, es conveniente y necesario en empresa tan atrevida.

Tras recibir esta carta, Pena propone ya fechas concretas para el encuentro en el Monasterio de Piedra, los días 26 y 27 de mayo de 1912, lo que la Asociación madrileña "acepta en un principio», como refleja su 
respuesta por carta fechada el 9 de mayo de este mismo año. Por esta carta sabemos también que la audiencia del 19 de marzo ante el rey tuvo efectivamente lugar:

Por nuestro querido compañero Viñas habrá Vd. sabido la buenísima acogida que S. M. el Rey nos dispensó, alentándonos en la hermosa obra que proyectamos.

\section{Primeras dificultades}

Todo parece ir sobre ruedas, por lo que Joaquim Pena confirma de nuevo las fechas de reunión en Piedra en su rápida respuesta fechada el 16 de mayo. Sin embargo, nada más recibir ésta, el secretario de la Asociación Wagneriana madrileña se ve obligado a enviar por su parte un escrito, en el que le comunica lo siguiente:

[...] tengo la contrariedad de manifestar a $\mathrm{Vd}$. que en la reunión que ayer noche tuvimos los Sres. que forman la Junta Directiva de esta Asociación, para tratar única y exclusivamente del proyectado viaje a Piedra, se vio la imposibilidad en que nos hallamos de concurrir a dicho Monasterio los días 26 y 27 del mes actual.

Como refiere a continuación, la comisión que la Asociación madrileña había nombrado para dicho viaje era la siguiente: Valentín de Arín (presidente), Manuel de Cendra (secretario), Manrique de Lara (bibliotecario), Rafael Ramos (tesorero) y Arturo Saco del Valle, José Borrell, José María Marañón y Fernando Gaisse (vocales). Además, también formaban parte de la comisión el arquitecto La Roca, "varios individuos de los más entusiastas entre los socios» y tres periodistas. Pero desgraciadamente ocurrieron varios imprevistos. En primer lugar, Valentín de Arín «entraba» precisamente el día 26 de mayo en la Real Academia de San Fernando, "acontecimiento que sus amigos y nosotros, sus compañeros de Junta, vamos a celebrar mucho». En segundo lugar, Manrique de Lara tenía los días 26 y 27 «un asunto de gran interés que precisa su presencia en la Corte». Saco del Valle, por su parte, dirigía conciertos esos dos días y, finalmente, José Borrell tenía guardia en el Hospital General. Por estas razones, la Asociación Wagneriana de Madrid propone varias fechas para reunirse: los días 2 y 3, 9 y 10 o 16 y 17 de junio. En la carta de 30 de mayo propondrá finalmente el 8 y el 9 de dicho mes, confirmando ya la salida de cada comisión «el viernes día 7 por la noche». 
13 Los telefonemas eran corrientes en aquella época y consistían en una comunicación que el comunicante entregaba por escrito en una oficina, trasladándose ésta por teléfono y siendo entregada por escrito al destinatario desde otra oficina de la localidad en la que el último habitase.
Sin embargo, dicho viernes 7 de junio, Manuel de Cendra se ve obligado a enviar un telefonema ${ }^{13}$ urgente, a las $10.50 \mathrm{~h}$, con el siguiente texto:

Suspendemos viaje por causa repentina, tres enfermos, detalles correo, perdón a todos. Manuel Cendra.

Dicho mensaje llega a Joaquim Pena dos horas más tarde, y éste responde inmediatamente de la siguiente manera:

Recibido telefonema una tarde, faltan breves horas salida tren. Imposibilitado reunir compañeros, adquirido billetes. Dispuesto todo, verificamos viaje forma convenida. Agradecemos acuda a Piedra alguno ustedes. Pena.

A este telefonema sigue un telegrama depositado el mismo día, a las $18.30 \mathrm{~h}$, con el siguiente mensaje:

Imposible acudir nadie por aumento dificultades lamentándolo de corazón nos unimos proyecto aprobando lo que ustedes acuerden en ésa. Cendra.

A pesar de los impedimentos surgidos desde Madrid, al día siguiente, es decir, el 8 de mayo, Joaquim Pena y los miembros de la comisión catalana se encuentran ya en el Monasterio de Piedra. Desde allí y a las 12 de la noche, envían a la Asociación madrileña el siguiente telegrama:

Agradecemos atención telegrama acompañamos a Vds. pensamiento lamentando forzosa ausencia esperamos conocer impresiones. Junta Directiva

El mismo 7 de junio, Manuel de Cendra, tras enviar su primer telefonema urgente, se había puesto a escribir una carta oficial, en la que le detalla los motivos de salud por los que tuvieron que suspender el viaje a Piedra. La esposa de Arín enfermó repentinamente y Manrique de Lara se encontraba en cama desde el día anterior. Los demás comisionados también tuvieron problemas y no les pareció adecuado que asistieran, «después de tanto pensarlo», sólo dos comisionados. Cendra aseguraba que celebraría de nuevo una Junta Extraordinaria,

[...] con objeto de decidir de una manera concreta quiénes y cuándo podemos garantizar a Vds. el viaje, poniéndonos a sus órdenes por la extorsión que seguramente les habremos ocasionado con aviso tan de última hora. 


\section{Emplazamiento del teatro y repercusión en la prensa}

Así, diez días más tarde, el 18 de junio de 1912, Joaquim Pena respondía con afecto a la carta de Cendra. En su escrito, mucho más extenso aún que el enviado en febrero, se mostraba solidario con Manuel de Cendra, haciéndose cargo de su situación e incluso disculpándose por haber partido finalmente a Piedra sin la comisión madrileña. En esta carta, Joaquim Pena realiza, sin ocultar su entusiasmo, un resumen detallado de todo lo acontecido en el Monasterio:

La excursión realizose con toda felicidad y las impresiones recibidas alimentaron nuestros mayores optimismos. El lugar que había sido escogido in mente para la realización de nuestro sueño, sólo por la fama de que goza Piedra, es realmente ideal, incomparable, y reúne todas las condiciones requeridas al objeto nuestro. Mi pobre pluma resulta impotente para hacer a Vds. una descripción de cuanto vimos y sentimos, cuanto gozamos y cuantos planes proyectamos. Pero nuestro compañero de excursión, el redactor crítico de arte y de La Publicidad, Sr. Jori, ha sabido expresar a maravilla en dicho periódico la quintaesencia de las impresiones recibidas, de los detalles del proyecto, de los trabajos verificados y del estado actual del asunto.

La Associació remite por paquete postal una partida de ejemplares de dicho artículo, "haciéndoles constar que todos los expedicionarios suscribimos gustosos como eco fiel de nuestro pensamiento, salvando por lo que atañe a mí particularmente las desmesuradas frases encomiásticas que me dedica, hijas más bien de una entrañable amistad que nos une, que mis méritos reales y positivos».

El emplazamiento para construir el Bayreuth españo/ en el Monasterio de Piedra parece ser del agrado de todos:

Recorrimos toda la posesión, buscamos y encontramos por fin el sitio ideal para nuestro objetivo, lejos del rumor de las cascadas, tomamos las oportunas medidas para el escenario, orquesta y espacio del espectador, planeamos la forma de realizar los trabajos; en una palabra, creo que dejamos resueltos in mente los detalles primordiales, de la misma manera que tenemos calculados ya los elementos artísticos para las representaciones, todo lo cual expondremos a Vds. en el momento que hubiera de entrarse en la parte práctica del asunto.

Además, Pena valora como positiva la entrevista mantenida con la familia Muntadas, que se encontraba allí en su práctica totalidad. Así, ya sólo quedaba un aspecto por resolver, 
[...] pero ésa es precisamente la cuestión capital: la parte económica de la empresa. Conocida ya la posibilidad de su realización artística, todo estriba en saber si contaríamos con los medios suficientes para llevarla a cabo. Mas eso no podíamos resolverlo allí por nosotros mismos, sino que nos era absolutamente necesaria la presencia de $\mathrm{Vds}$. a fin de cambiar opiniones sobre los tanteos verificados y sobre la posibilidad de levantar el capital indispensable.

\section{Planes de explotación del teatro}

Joaquim Pena insiste, una vez más, en la necesidad de apoyo por parte de la Asociación Wagneriana de Madrid:

Por lo que a nosotros atañe, no he de hacer sino ratificarme en cuanto exponía bien claramente en mi carta de Febrero acompañando al proyecto de bases. Aquí puede hacerse algo, pero precisa la participación principalísima y, sobre todo, la iniciativa de Vds. para convencer a nuestra gente. A Vds. toca, pues, exponer su opinión sobre el particular, teniendo en cuenta todos los resortes que en ésa puedan tocarse, oficiales y particulares, con esperanzas de éxito.

Para hacer frente a los gastos, Pena propone «lanzar cuanto antes una emisión de acciones» mientras se trabaja «con alma y vida para cubrirla lo antes posible», recomendando, además, realizar un presupuesto de gastos lo más concreto posible:

Para saber la cantidad que hay que pedir, precisa un presupuesto aproximado de gastos, y esto no puede deducirse de nuestra visita aislada a Piedra, sin temor a error gravísimo. Es más, ni aun en el supuesto de habernos reunido allí ambas comisiones acompañadas del personal técnico correspondiente, creo que hubiera sido posible establecer aquél de una manera exacta, debido a mil circunstancias imprevistas, entre ellas la cuantía del material escénico, que forzosamente hay que pedir al extranjero, para lo que es preciso ante todo pedir precios o, mejor aún, llamar a un perito en la materia para que los dé sobre el terreno.

Joaquim Pena va más allá y propone un primer borrador del proyecto concreto que resume los conceptos presupuestarios:

Lo único que nosotros podemos ahora comunicar a $V$ ds. es una opinión hija más bien de la impresión personal que basada en un cálculo real y efectivo, en el entendido de que sólo han de tomarla $V d s$. a beneficio de inventario. Resumiéndola, para abreviar, dividimos el coste total, prescindiendo de momento del gasto material de cada representación en dos conceptos: 
1. ${ }^{a}$ construcción del teatro, en condiciones de ser explotado en años sucesivos, única manera de asegurar a los accionistas un negocio que de otra suerte es forzosamente ruinoso.

2. ${ }^{a}$ habilitación del Monasterio de Piedra para hospedar el número conveniente de personas.

En cuanto al primer extremo, hemos deducido que la sala completamente cerrada costaría menos de lo que temimos, debido a las condiciones naturales del sitio designado y a la facilidad de proporcionarnos la misma finca toda la piedra necesaria, si bien el principal elemento de construcción debiera ser la madera y parte de hierro. El coste del escenario sería fácil de [calcular] por lo que se refiere a estos elementos, pero más difícil respecto a la complicada maquinaria, para lo que me atengo a lo que he expuesto más arriba.

También calcula el número de espectadores que podrían allí hospedarse, como si del Bayreuth españo/ se tratara:

Por lo que hace al segundo extremo, el hospedaje en Piedra, recorrimos el Monasterio y sacamos la conclusión de que aunque hoy no está habilitado más que para un par de centenares de personas, hay allí cabida suficiente para muchísimos centenares más, verificando las obras necesarias. Hay local en grande por habilitar, y todo es cuestión de tabiques, no de paredes ni techos, calculando en 2.000 el número de espectadores. Así creemos que cogerían en el Monasterio, si no todos, que es un imposible, por lo menos unas dos terceras partes, y para el resto se puede contar con los grandes establecimientos de Alhama, distante hoy sólo tres cuartos de hora del Monasterio, merced a un buen servicio de automóviles ya establecido. Por lo tanto, con un buen maestro de obras y un contratista de muebles necesario, podría fijarse con bastante exactitud la cifra total respecto de este punto.

Como consecuencia de todo lo expuesto, Pena es aún más directo y, después de repetir que «no nos declaramos competentes en la parte técnica», calcula que el capital inicial podría ser de «por lo menos un millón de pesetas», cantidad esta que habría después que ampliar:

La cifra es respetable, no hay duda, y aun así no respondemos de quedarnos cortos, poco o mucho, pero también consideramos que en más o menos tiempo puede llegar a ser un negocio.

¿Cómo conseguir este millón? El presidente de la Associació Wagneriana catalana vuelve a lanzar otra idea:

Si la iniciativa privada no basta para ello, es cuestión de convertirlo en obra nacional, abriendo suscripciones en todas las grandes capitales y reclamando 
el apoyo oficial del Rey y del Estado, Diputaciones y Ayuntamientos más interesados y Corporaciones de cultura.

Pena no duda del éxito que, incluso en el plano internacional, podría tener el proyecto:

Del extranjero me escriben ya pidiendo detalles y no hay duda que la empresa puede llegar a tener una resonancia mundial que nos permita verificar un número de representaciones superior a los cálculos más optimistas.

El fundador de la Associació Wagneriana termina su escrito animando de nuevo a los madrileños, instándoles a una acción urgente y dándoles un «ultimátum»:

Ahora tienen Vds. la palabra. La capital de España es la que debe gritar iadelante! o tocar a retirada. Nosotros estamos siempre dispuestos a formar en las avanzadas.

Como que no nos queda más tiempo que perder, yo ruego a $V d s$. que tomen una resolución definitiva sobre el particular a la mayor brevedad posible antes de que se inicie la desbandada del verano. Reúnanse ustedes en seguida, cambien impresiones sobre lo que llevamos expuesto, lléguense personalmente a Piedra, que no está tan lejos de ésa, rectifiquen nuestros equivocados puntos de vista, expóngannos sus impresiones y razonamientos y borroneen las bases definitivas de la nueva sociedad artística o, en último término, desengáñennos $V d s$. de una vez, para abandonar en la región de los sueños irrealizables una idea que hoy ya empieza a trascender demasiado al público.

\section{Una amarga despedida}

Tras este extenso escrito, la Asociación Wagneriana de Madrid se reúne de nuevo a finales de junio y, el 25 de este mes, Manuel de Cendra escribe una carta Joaquim Pena que comienza así:

Ayer noche nos reunimos por segunda vez la Junta Directiva de esta Asociación para tratar ampliamente, con el interés que nos inspira el proyecto de representaciones de Parsifal en el Monasterio de Piedra, y con objeto de poder contestar a las preguntas y razonadas proposiciones que en nombre de la Wagneriana de Barcelona nos formula $\mathrm{Vd}$. en su atta. carta, fecha 18 del pasado.

Cendra relata la precariedad en materia de recursos que apoyen la cultura en Madrid, así como la falta de sensibilidad artística de la clase política: 
En Madrid, el capital y el arte andan siempre a cachetes; ${ }^{14}$ aquí no existe, y es una necesidad cada día mayor un salón de conciertos, ni modesto siquiera, y en fin, nosotros que tenemos también en estudio el edificar un templo al arte musical; para poder realizar tan sensato proyecto, hemos de presentarlo como un negocio, es decir, edificando la Sala de Conciertos en un patio de una gran casa de vecindad, cuyas tiendas, almacenes y demás dependencias mercantiles aseguren al escamado accionista un interés a su dinero, único medio de conseguir éste.

El presidente de la Asociación Wagneriana madrileña ve inviable conseguir la cantidad de dinero necesaria para el proyecto:

Nosotros entendemos que es imposible, que no hay manera de garantizar ese millón de pesetas que $V d s$. con muy acertado cálculo estiman necesario y desde el momento en que sólidamente no se garantice aquél y se marque un interés seguro a las acciones no se obtendrá en Madrid ni la más modesta cifra para el proyecto, que si a los wagnerianos nos hace meditar, qué no hará a los que todo lo ven con la desconfianza natural de un riesgo posible.

Cendra relata cómo ha tratado personalmente el asunto con políticos madrileños de su confianza y cómo éstos exponían la imposibilidad de encontrar subvenciones culturales, pues si ya era difícil encontrar ayudas para fomentar las «manifestaciones de arte nacional», más difícil sería aún conseguir apoyos para acciones culturales relativas a un músico «extranjero».

Los miembros de la Asociación Wagneriana madrileña intentaron incluso buscar ayuda individualmente, como consta en alguna carta privada de Manuel de Cendra a familiares y amigos encontradas, curiosamente, en el Fons de Joaquim Pena de la Biblioteca de Catalunya. Sin embargo, como expresa el secretario de la institución madrileña, los esfuerzos parecían haber sido en vano:

Individualmente todos los Señores que constituimos la Directiva lo hemos estudiado también; hemos hecho gestiones aisladas con personas influyentes, obteniendo de todos la misma respuesta al problema; ésta es: calificar de grandioso pensamiento y digno proyecto de unas agrupaciones de la naturaleza de las nuestras, pero (y este pero es desconsolador), a juicio de los consultados, irrealizable por la inmensa dificultad de encontrar dinero para la empresa.

Cendra hace también alusión a los problemas de infraestructura existentes en Madrid, como la ausencia de una Sala de Conciertos (Ios subrayados son de Cendra):
14 Este y los siguientes subrayados son los originales. 
En Madrid, el capital y el arte andan siempre a cachetes; aquí no existe, y es una necesidad cada día mayor, un Salón de Conciertos, ni modesto siquiera y, en fin, nosotros que tenemos también en estudio el edificar un templo al arte musical; para poder realizar tan sensato proyecto, hemos de presentarlo como un negocio, es decir, edificando la Sala de Conciertos en un patio de una gran casa de vecindad, cuyas tiendas, almacenes y demás dependencias mercantiles aseguren al escamado accionista un interés a su dinero, único medio de conseguir éste.

La cuestión sería trasladar este aspecto consumista al proyecto del Monasterio:

¿Cómo puede presentarse el proyecto de Piedra, dándole caracteres financieros? Nosotros entendemos que es imposible, que no hay manera de garantizar ese millón de pesetas que $V d s$. con muy acertado cálculo estiman necesario, y desde el momento en que sólidamente no se garantice aquél y se marque un interés seguro a las acciones, no se obtendrá en Madrid ni la más modesta cifra para el proyecto [...].

Así, el presidente de la Asociación madrileña relata cómo los wagnerianos de la capital han acabado por rendirse, despidiéndose así del ambicioso proyecto en esta su última carta:

Con claridad debemos decirles que serán estériles cuantos esfuerzos en Madrid se realicen; la opinión es contraria al proyecto por la enorme cifra que a él hay que aportar, la que sólo un capitalista amante de nuestra causa puede ofrecer solucionando de este modo el difícil problema monetario que a nuestro juicio se presenta.

Y aquí acaba el sueño del proyecto de Piedra, concebido como un Bayreuth ibérico, como un lugar de peregrinaje para los wagnerianos nacionales pero con decidida proyección internacional, símbolo de los últimos coletazos de un movimiento de aparición tardía pero de tremenda vitalidad - el wagnerismo español - representado en sus dos polos fundamentales: Madrid y Barcelona.

Paloma Ortiz-de-Urbina Universidad de Alcalá paloma.urbina@uah.es 
Un «Bayreuth español» Para 1913: Wagnerianos de Madrid y Barcelona en un PROYecto común

En 1911, la Associació Wagneriana de Barcelona y la Asociación Wagneriana de Madrid se unen en un proyecto común: la construcción de un teatro wagneriano en Zaragoza, en lo alto de una montaña, junto al Monasterio de Piedra, con cabida para unas dos mil personas, en el que pudiera representarse la última obra de Richard Wagner, Parsifal, cuyo plazo de protección iba a expirar en toda Europa el 1 de enero de 1914. Como si de un Bayreuth español se tratase -lugar de peregrinaje nacional con proyección internacional-, se idea el plan de explotarlo en años sucesivos, pensando en habilitar el propio monasterio para hospedar a los posibles peregrinos. Los wagnerianos de entonces remueven cielo y tierra para obtener fondos y conseguir que el propio rey de España, Alfonso XIII, se interese por la idea y se entreviste con ellos el 19 de abril de 1912. El presente artículo analiza los pormenores de dicho proyecto, a través de la correspondencia inédita mantenida entre ambas asociaciones wagnerianas desde el 4 de julio de 1911 hasta el 1 de julio de 1912.

Palabras clave: wagnerismo, Associació Wagneriana de Barcelona, Asociación Wagneriana de Madrid, Joaquim Pena, proyecto de Piedra, Bayreuth.

A "Spanish Bayreuth" for 1913: Wagnerians from Madrid and Barcelona in a common PROJECT

In 1911 the Wagner Society in Barcelona (Associació Wagneriana de Barcelona) and the Wagner Society in Madrid (Asociación Wagneriana de Madrid) decided to join in a shared project: their intention was to build a Wagnerian theater in Zaragoza, on the top of a mountain near the Monasterio de Piedra - a Cistercian monastery located in a natural reserve-, which would be able to accommodate around 2,000 visitors and adequately host the representation of Wagner's last opera, Parsifal, since its copyright would expire throughout the whole of Europe on $1^{\text {st }}$ January 1914 . As if it were a Spanish Bayreuth - a national pilgrimage destination with international resonance-, it was planned to make use of it in future years and even prepare the monastery to host the potential pilgrims. The Wagnerians of the time searched everywhere in order to obtain the necessary funding and awoke the interest of no less than the King of Spain, Alfonso XIII, who even consented to an interview with them on $19^{\text {th }}$ April 1912. The present paper aims to explore the details of this project on the basis of the unpublished correspondence which both Wagnerian societies maintained from $4^{\text {th }}$ July 1911 until $1^{\text {st }}$ July 1912.

Keywords: Wagnerism, Wagner Society in Barcelona, Wagner Society in Madrid, Joaquim Pena, Bayreuth, proyecto de Piedra. 
El proyecto del Bayreuth español de 1911, Paloma Ortiz-de-Urbina

\author{
ANEXO. \\ CORRESPONDENCIA INÉDITA ORIGINAL MANTENIDA \\ ENTRE LA ASOCIACIÓN WAGNERIANA DE MADRID \\ Y LA ASSOCIACIÓ WAGNERIANA DE BARCELONA
}

(1911-1912)

Se transcribe a continuación la correspondencia completa mantenida entre la Asociación Wagneriana de Madrid (AWM) y la Associació Wagneriana de Barcelona (AWB) desde el 4 de julio de 1911 hasta el 25 de junio de 1912, encontrada en el Fons Pena de la Biblioteca de Catalunya. Las cartas se numeran según orden cronológico, para una mejor consulta de las mismas, especificando el tipo de documento transcrito. En el fondo de Joaquim Pena se encontró toda la correspondencia original (tanto cartas, escritas a mano o mecanografiada, como telegramas o telefonemas) remitida por la AWM a la Associació barcelonesa. En el caso de las cartas enviadas por la AWB a la Asociación Wagneriana madrileña, encontramos borradores escritos a mano por Joaquim Pena. Se conserva la ortografía original de las cartas y se respetan las normas gramaticales vigentes en el momento de redacción de las mismas, añadiendo en caso necesario la versión correcta entre corchetes y actualizando tan sólo las tildes ortográficas. Se especifican también entre corchetes los datos fácilmente presumibles omitidos en los borradores. Los subrayados de las cartas son originales. No se transcriben los subrayados de las cartas enviadas por la AWM a la AWB, realizados a lápiz por el destinatario, Joaquim Pena.

1. Madrid, 4 de julio de 1911. Carta original mecanografiada de Manuel de Cendra, con membrete y dirección de la AWM.

2. Barcelona, julio de 1911. Borrador manuscrito de Joaquim Pena.

3. Madrid, 12 de enero de 1912. Carta original mecanografiada de Manuel de Cendra, con membrete y dirección de la AWM.

4. Barcelona, febrero de 1912. Borrador manuscrito de Joaquim Pena.

5. Madrid, 11 de marzo de 1912. Carta original manuscrita de José María Marañón, con membrete de la AWM.

6. Madrid, 1 de abril de 1912. Carta original mecanografiada de Manuel de Cendra, con membrete y dirección de la AWM.

7. Madrid, 9 de mayo de 1912. Carta original mecanografiada de Manuel de Cendra, con membrete y dirección de la AWM. 
8. Madrid, 20 de mayo de 1912. Carta original manuscrita enviada por Manuel de Cendra, con membrete de la AWM.

9. Madrid, 30 de mayo de 1912. Carta original mecanografiada enviada por Manuel de Cendra, con membrete de la AWM.

10. Madrid, 7 de junio de 1912; 10.50 h. Telefonema enviado por Manuel de Cendra a la AWB.

11. Barcelona, 7 de junio de $1912 ; 13.00$ h. Telefonema enviado por Joaquim Pena a la AWM.

12. Madrid, 7 de junio de 1912; 18.30 h. Telegrama enviado por Manuel de Cendra, desde Madrid a Piedra, a Joaquim Pena y recibido por este último en la oficina de Alhama.

13. Madrid, 7 de junio de 1912; 24 h. Telegrama enviado por la Junta Directiva de la AWM a Joaquim Pena, probablemente en respuesta a otro telegrama enviado por este último el mismo 7 de junio, entre las $18.30 \mathrm{~h}$ y las $24.00 \mathrm{~h}$ y recibido en la oficina de Alhama.

14. Madrid, 7 de junio de 1912. Carta original mecanografiada enviada por Manuel de Cendra con membrete de la AWM.

15. Barcelona, 18 de junio de 1912. Borrador original manuscrito enviado por Joaquim Pena.

16. Madrid, 25 de junio de 1912. Carta original mecanografiada enviada por Manuel de Cendra, con membrete de la AWM.

17. Madrid, 1 de julio de 1912. Carta original mecanografiada enviada por Manuel de Cendra, con membrete de la AWM. 
Madrid, 4 de julio de 1911

Sr. D. Joaquín Pena:

Barcelona

Muy distinguido Sr. mío:

Mucho tiempo hace que tenía la intención de dirigirme a $V$. para darle cuenta de la constitución en Madrid de la Asociación Wagneriana que, tras no pequeña lucha, he organizado, teniendo la inmensa satisfacción de verla ya constituida con una pujanza extraordinaria y un gran entusiasmo por parte de los 1.550 socios con que hoy contamos, cada vez más entusiastas y defensores de la causa Wagneriana en sus dos manifestaciones literaria y musical.

El deseo de poder transmitir a un mayor número de progresos de esta naciente agrupación ha sido la causa de demorar mi carta, que hoy le dirijo en vista de las manifestaciones de adhesión y entusiasmo por $\mathrm{V}$. demostradas en sus entrevistas con nuestro compañero Conrado del Campo, durante su estancia en Barcelona con la Sinfónica.

Nuestros proyectos para este invierno se los transmitiré brevemente: El más importante será la celebración en Marzo o Abril de unos Ciclos wagnerianos, con cantantes alemanes, dirigidos nada menos que por el Dr. Hans Richter, la mayor autoridad del mundo. Antes, en Octubre o Noviembre, celebraremos con la Orquesta Sinfónica, tres conciertos, dirigidos seguramente (pues ha aceptado en principio) por Félix Mottl, también autoridad indiscutible, y durante el año varias conferencias, dadas por personas de gran prestigio, dedicando una de ellas exclusivamente al estudio y vulgarización de los «Maestros Cantores», cuya obra vamos a oír durante la próxima temporada en el Teatro Real. De este Teatro, como verá $\checkmark$. por la adjunta circular, hemos conseguido unos abonos especiales para nuestros socios, con la considerable rebaja del $50 \%$ en casi todas las localidades, dedicando para ello un día fijo a la semana en el que sólo escucharemos obras de Wagner, oyéndose la Tetralogía por su orden natural. Y en fin, haremos cuanto esté a nuestro alcance y bolsillo, pues no es ésta la menor dificultad que se nos presenta al tener una cuota mensual tan pequeña, como es la de 2 ptas que se viene satisfaciendo.

Esta Asociación, identificada con la de Vds., no tiene otro deseo que adherirse a ella, empezando por aplaudir la meritísima labor por Vds. realizada, especialmente en la publicación de los poemas, labor interesantísima y de mucha importancia, que estamos nosotros empezando a realizar.

De todo lo traducido por esa Wagneriana, tengan la bondad de mandar un ejemplar con destino a la Biblioteca de nuestra Asociación, y hacernos saber su importe para girárselo a vuelta de correo, así como sus Estatutos. También le agradeceré me transmita los nombres de los señores que forman la Junta Directiva de esa Asociación, como yo tengo el gusto de hacerlo acompañando a la presente con un ejemplar de los Estatutos por los que nos regimos. 
Queda suyo afmo. S.S.

Q.B.S.M.

[Firma autógrafa de Manuel de Cendra]

Secretario

2

[Barcelona], Julio 1911

Sr. Secretario de la A.W. de Madrid

Muy Sr. mío y de mi consideración más distinguida:

Transmitido a este Consejo Directivo por nuestro distinguido consocio y ex Presidente D. Joaquín Pena la comunicación de $\mathrm{Vd}$. participando la constitución y proyectos y la entidad de que $\mathrm{Vd}$. es digno secretario, tengo el honor de manifestarle en nombre de la Asociación Wagneriana de Barcelona, que recibimos y devolvemos con el mayor entusiasmo el atento saludo que nos dirigen congratulándonos en extremo por la fundación de una nueva Asociación Wagneriana en Madrid, que agradecemos en todo lo que valen su valiosa adhesión y cariñosas frases encomiásticas de nuestra modesta pero constante labor durante los diez años que llevamos de existencia y que hacemos votos porque nuestra ilustre compañera madrileña goce de la más próspera y larga vida para el mayor esplendor artístico que nos inspira y hermana.

Al propio tiempo y satisfaciendo sus justos deseos, tenemos el mayor gusto en ofrecer a esa Asociación la colección completa de nuestras publicaciones y comunicarle el envío de todas cuantas aparezcan en lo sucesivo, considerándonos muy honrados, con que la de Vds. se digne a hacer lo propio con las suyas.

[Joaquim Pena]

3

Madrid, 12 de enero de 1912

Sr. D. Joaquín Pena

Asociación Wagneriana

Barcelona

Muy distinguido señor mío:

Nuestro compatriota, el eminente Sr. Viñas, me ha dado cuenta particularmente del grandioso proyecto que $V d s$. tienen y que nosotros aplaudimos sin reservas respecto a la próxima representación en España, del sublime «Parsifal».

De tan hermosa idea he dado cuenta a la Directiva de esta Asociación y todos, unánimemente, han prodigado su aplauso a este proyecto, que aprobamos en todas sus partes, dispuestos a colaborar con Vds. en todo lo que nuestras fuerzas permitan, deseando tener en Mayo una reunión en el Monasterio de Piedra, como Vds.

DOl10.1344/Materia2014.8.3 
proponen, y antes de esa época en Madrid, si lleva $\mathrm{Vd}$. a la práctica su proyectado viaje a esta corte, según indicación hecha por el Sr. Viñas.

En esta entrevista se trazaría el proyecto con algún detalle más, pues hay que tener presente que aunque, la representación se haya de celebrar en Junio de 1913, sólo queda año y medio, tiempo nada más que suficiente, tal vez escaso, para organizar tanto como es preciso llevar a la práctica venciendo los innumerables obstáculos que se han de encontrar en empresa de tanta magnitud, sobre todo para la formación de la Sociedad que construya el teatro, único medio posible de poder llevar a la escena este maravilloso drama.

Por lo tanto, en nombre de la Junta Directiva y, puesto que el Sr. Viñas nos ha dado el nombre de $\mathrm{Vd}$. como principal iniciador de esta idea, a $\mathrm{Vd}$. me dirijo para que tenga la bondad de expresar al Consejo Directivo de esa Sociedad hermana, nuestra adhesión más incondicional en este proyecto, dispuestos a colaborar en él con todo el amor y entusiasmo que la causa requiere, en la seguridad de que no hemos de escatimar sacrificio alguno de orden económico e intelectual uniendo todas nuestras fuerzas al feliz resultado de tan hermoso pensamiento.

Si la entrevista primera a que me refiero anteriormente, no pudiera celebrarse en breve plazo, tenga $\mathrm{Vd}$. Ia bondad de indicarnos por carta, algo de lo que hayan pensado para dar cuerpo a esta idea, en su parte prosaica y material, que si bien es la más ingrata a tratar, desgraciadamente en cuestiones de arte es en la que siempre nos estrellamos todos.

$Y$ me refiero, naturalmente, al proyecto de Sociedad por acciones, que aporte el capital necesario para tan grande obra.

Sólo me resta enviar a $\mathrm{Vd}$. particularmente mi enhorabuena más sincera ofreciéndome su más entusiasta colaborador y affmo. amigo S.S.

Q.B.S.M.

El Secretario,

[Firma autógrafa de Manuel de Cendra]

4

Febrero 1912

Sr. D. Manuel de Cendra - Secretario de la A.W. - Madrid

Muy Sr. mío y de mi consideración más distinguida:

Debo comenzar por darle mis más cumplidas explicaciones por mi tardanza en contestar a las dos afectuosas cartas que de $\mathrm{Vd}$. Ilevo recibidas. La primera, del pasado verano, llegó a mis manos momentos antes de ausentarme de ésta, y sin tiempo para más la transmití a la Junta de la Asociación para que cumpliese con $\checkmark d s$. en su nombre y en el mío y les remitiera nuestras publicaciones. A principios de invierno proyectaba yo hacerlo directa y extensamente para poder, al paso que cumplía mi deuda con $\mathrm{Vd}$., exponerle el atrevido plan que nos ocupa en estos momentos y que ya de tiempo hervía en mi imaginación. Pero he pasado esta última temporada absorbido por importantes asuntos particulares, con no pocos que- 
braderos de cabeza, en vista de lo cual expuse el proyecto a mi entrañable amigo el tenor Viñas momentos antes de marchar a cumplir sus compromisos en ésa, para que adelantara su divulgación y ganáramos así tiempo. El insigne artista supo cumplir tan a maravilla su cometido, que poco después me sorprendía gratamente nueva carta de $\mathrm{Vd}$. otorgando una acogida tan favorable al proyecto por parte de esa Asociación. Desde aquel momento fue una idea fija corresponder a la confianza con que me honraban $V d s$. formulando concretamente el proyecto en una serie de bases para someterlas a su más alto criterio y consiguiente aprobación o modificación. Con todo, ha pasado más de un mes, durante el que los asuntos a que antes me refiero, en vez de aligerarme me han agobiado más todavía, como bien le consta al amigo Viñas al que rogué me excusara cerca de Vds. por la tardanza. Por fin me he decidido a romper el fuego, pues no hay tiempo que perder, y a corresponder de una vez ya con $\mathrm{Vd}$. dándole gracias por sus atenciones y rogándole se digne aceptar el testimonio de mi franca amistad al par que mi más entusiasta admiración por su magnífica labor en pro de nuestra causa común que con tanto éxito viene realizando esa asociación hermana.

En un rollo separado que certifico por este mismo correo, recibirá $V d$. el referido proyecto de bases, que después de redactado he leído al Consejo directivo de nuestra Asociación y éste ha aprobado ya en todas sus partes. Allí encontrará Vd. expuesta mi idea en líneas generales, sólo para marcar la orientación sin descender a detalles demasiado prematuros todavía. Y como aplicación o glosa de lo que allí expongo voy a permitirme molestar aún su atención con unas cuantas consideraciones con objeto de facilitar nuestra mutua inteligencia y así podamos fructificar la semilla cuanto antes. El caballo de batalla será, sin duda, como Vd. ha visto bien desde un principio, el aspecto económico. Dado que forzosamente ha de ser cuestión de construir un teatro y dotarlo de tantos y tan complicados accesorios como exige su objetivo, el capital que para ello se requiere representa una suma muy respetable. ¿Podremos llegar a reunirla? Ahí está el problema, pero creo que no tiene nada de particular ni difícil intentarlo, guardándonos de dar un paso en firme hasta tener asegurado en buena parte el éxito de la suscripción, para evitarnos un ridículo fracaso. Es cuestión de pulsar al instante la opinión en nuestros dominios respectivos y ver cómo responde. Llevo doce años tirando del carro, luchando constantemente y sacrificando tiempo y dinero para cosechar burlas y disgustos al principio, bien que después haya venido el conocimiento tardío pero franco y general, acompañado de un cúmulo de desmesuradas alabanzas, inútiles y hasta contraproducentes con apoyo material escaso. En la época de mayor apogeo, cuando prodigábamos las sesiones y conciertos, no llegamos a 400 socios; después, cuando estudiadas detenidamente todas las obras de Wagner y sin elementos para crear el teatro wagneriano que soñábamos, nos convertimos exclusivamente en sociedad editorial, hemos quedado constituyendo un núcleo de un centenar, con otro centenar que desde fuera nos ayuda en la edición de las partituras. Pero ¡si supiera $\mathrm{Vd}$. la lucha que nos cuesta cada vez para colocar el resto de tan costosas ediciones!

Por todo ello, jamás hubiera pasado por mi mente una empresa tan arriesgada como la que proyectamos sin la creación de la entidad de Vds. 
Al tener noticia de su existencia, pronto se me ocurrió que debíamos unirnos si queríamos celebrar el centenario de una manera digna sin las mogigangas [mojigangas] propias de casos análogos. Con la plétora de vida, con el entusiasmo que Vds. traen y con el temperamento más desprendido que les caracteriza, creo que tenemos bastante ganado. Para que salgamos adelante, es preciso que mi consocio Madrid, es decir, los pudientes de toda España que ahí tienen su residencia, carguen con buena parte del empréstito. Bilbao puede también hacer bastante, y en cuanto a Barcelona, yo he de poner alma y vida en remover hasta las piedras para ver si esta vez siquiera, por la trascendencia de la cosa y por la misma emulación de $V d s$., nuestras clases mercantiles, que son aquí los verdaderos potentados, se dignan a ayudarnos y nos evitan el ridículo. Éste es mi parecer, sin ambages ni rodeos, como sastre que conoce el paño, y por eso me apresuro a exponérselo francamente para fijar bien el terreno que pisamos.

Es preciso, en consecuencia, lanzar bien la cosa. Meter en esa Junta organizadora, lo más numerosa posible, unos cuantos nombres de gente joven que arrastra, y jalearlo de lo lindo en la prensa. Y así, despertando la emulación y estimulando la vanidad, podremos hacer llegar a muchos a donde no conseguiría llevarlos el amor al arte. Si la cosa arrancara, no hay duda que luego el éxito de los festivales puede darse por descontado. Y si no arranca, podremos siempre los organizadores tener la conciencia tranquila de que intentamos honrar la memoria del Genio, de la manera más digna y que, si se perdió, no fue por culpa nuestra.

Perdóneme estas digresiones hijas de mi mismo deseo de triunfar y vayamos al grano. Repito que mi exposición del plan no es más que un proyecto, que no tengo criterio cerrado en ningún extremo del mismo y que, por tanto, así en el fondo como en la forma, a su superior criterio e inteligencia me remito, en la seguridad de que con las modificaciones y adiciones con que sabrán enriquecerla van a dejar la cosa perfectamente viable. Por eso no he querido fijar detalles, ni pretender por un momento imponer normas de acción a esa junta organizadora que debe ser la soberana absoluta. Sólo en un punto sí me ha parecido necesario precisar concretamente, y es en la cuestión del lenguaje. La gran incomprensión de las obras de Wagner por parte de muchos wagnerianos inclusive estriba en la falta de atención al drama, suplida por un exceso de atención a la música, fomentado por las continuas representaciones en lengua extraña. Pues bien, creo que esta vez hay que poner la primera piedra, como la hemos puesto ya nosotros en el Liceo; hay que barrer a marchas forzadas la ignominia de la representación en italiano y no es lógico tampoco abrir la puerta al alemán, ni a pretexto de admirar interpretaciones de grandes artistas. El descomunal relato de Gurnemanz y la terrible lamentación de Amfortas no pueden menos de resultar una solemne lata a todo aquel que no siga palabra por palabra lo que dicen. Hay que tener además en cuenta que sólo el primer acto dura dos horas, y espero que no consentirán Vds. que se corte un solo compás, pues éste es mi otro caballo de batalla. Por eso es que hago hincapié tan sólo en este punto.

A esto nos objetarán sin duda: ¿y los artistas?, ¿y la traducción? Que cubran la suscripción y no se preocupen por el resto, que todo lo demás saldrá. Me empe- 
ñé en hacer cantar en catalán a la Pasini Vitale, y todo el mundo quedó sorprendido al oír lo que hubiera creído siempre imposible. Conozco a muchos cantantes italianos que hablan el español más que suficientemente bien para poder echar mano de ellos.

En cuanto a la traducción castellana, a Vds. toca decidir. Permítanme sólo un consejo: mucho cuidado con las grandes firmas, los literatos eminentes, pues por el afán de crear, son los que acostumbran a desfigurar más el original. Y si nadie se veía con fuerzas, también aquí intentaríamos sacar adelante la empresa.

Otra de las cuestiones perentorias es la de tratar con el propietario. Yo me he adelantado, comenzando ya los trabajos, pues como no ignorarán se trata de un paisano nuestro, y aunque se pase gran parte del tiempo en Calatayud y cuente ya 88 años, sus más próximos allegados están aquí y con ellos estamos ya gestionando para que le convenzan. En cuanto haya algo fijo se lo comunicaré a Vd. Uno de sus más próximos allegados, compañero nuestro y que ha escrito muchos trabajos wagnerianos, se ha encargado de tan delicada misión.

Por los motivos que expongo al principio no creo poder trasladarme por ahora a ésa como proyectaba.

Pero allá para el mes de Mayo, aprovechando un par de fiestas, podríamos reunirnos todos en Piedra, según propongo en el proyecto y allí dejar establecidas las verdaderas [bases] para convertirlo en realidad.

Ruégole, pues, que se sirva acoger con la mayor benevolencia y transmitir a sus compañeros mi plan que no está más que borroteado y que no tenga ninguna clase de reparo en hacer al mismo cuantas observaciones aconseje su criterio en beneficio del propio ideal.

Quedo verdaderamente ansioso de conocer la opinión de Vds. y considero inútil repetir que me tienen enteramente a sus órdenes por todos conceptos.

Sírvase transmitir mis más afectuosos saludos a mis entrañables amigos Félix y Pepe Borrell del Campo y demás señores de esa distinguida Junta haciendo votos para que la arriesgada empresa constituya para todos el lazo de la más firme amistad y ofreciendo a $\mathrm{Vd}$. Ia suya incondicional, quedo su affmo.

\section{S.S.S.}

[Joaquim Pena]

\section{5}

Madrid, Lunes 11 de marzo / 1912

Señor Don Joaquín Pena

Muy señor mío:

Me tomo la libertad de escribirle porque estando ausente el amigo Cendra asumo las funciones de secretario de esta asociación; recibimos su atenta carta y las bases; dentro de pocos días regresará Cendra y contestará a su carta en cuanto a las bases. Yo di lectura en la junta que celebramos el día 4 y todos estuvimos conformes en aplaudir el noble espíritu que los anima; respecto a su realización 
material se ha hecho lo siguiente: tenemos pedida una audiencia al Rey para cuando regrese de Lisboa el amigo Viñas y juntos a ver si le interesamos en el grandioso proyecto; así mismo vamos a ver al ministro con el mismo objeto. Con motivo de ausencias está esta junta bastante incompleta.

Dentro de breves días estaremos casi todos reunidos y entonces tendremos otra reunión y emprenderemos la acción y de ello les daremos cuenta a esa simpática asociación hermana.

Los amigos Félix y Pepe Borrell me encargan le salude y le anime a hacernos una visita coincidiendo con la venida del Orfeó. Tendríamos todos un gran gusto y placer en ello. La opinión ha acogido con gran júbilo la noticia de la venida de tan notable corporación.

Disponga de mí como de un verdadero amigo y servidor.

Muy suyo,

[Firma autógrafa de José María Marañón]

s/c Lista 3, $3^{\circ}$

6

Madrid, $1 .^{\circ}$ de abril de 1912

Sr. Don Joaquín Pena

Barcelona

Muy distinguido Sr. mío:

Cuando se recibió su extensa e interesante carta del 26 de Febrero último, estaba yo ausente y el Secretario que interinamente quedó sustituyéndome, dio cuenta a la Directiva de la citada carta y de las amplias y razonadas Bases que la acompañaban. Dicho Señor comunicó a $\mathrm{Vd}$. acto seguido, el agrado e interés con que la Junta había escuchado la lectura del hermoso proyecto ideado por la Asociación hermana de Barcelona, dejando en suspenso el tratar ampliamente de este asunto hasta mi regreso (que tuvo lugar el 20 del pasado mes), cosa que de veras he agradecido a mis compañeros de Junta.

Al tener yo conocimiento de este acuerdo, convoqué a sesión que celebramos el 29 de pasado Marzo, en la que se acordó:

1. Solicitar de S. M. el Rey una audiencia para el día 19 del actual, en cuya fecha estará en Madrid el Sr. Viñas de paso para su excursión artística de Murcia, y con él acudir a Palacio una comisión de esta Wagneriana, que exponga a S. M. el proyecto, demandando su reapoyo, en la forma más práctica que pueda conseguirse.

2. Nombrar una comisión que acuda a reunirse con la de Vds. en el Monasterio de Piedra, en la fecha de Mayo o Junio que ambas entidades convengan, estudiando sobre el terreno, con el entusiasmo peculiar en nosotros, el modo de dar forma al proyecto y cambiar pareceres e impresiones que seguramente serán los mismos, pues idéntico amor nos hermana; y 
3. ${ }^{\circ}$ Comunicar el pensamiento que tenemos a todas aquellas personas que por su influencia, posición social, amor al divino arte, o dinero factible, nos sirvan en su día y conozcan ya la idea grande que nos mueve y reúne, prestándola su apoyo, que por pequeño que cada cual nos otorgue, es conveniente y necesario en empresa tan atrevida.

Todo esto rápidamente, pues el tiempo es más breve de lo que a primera vista parece.

A medida que vayamos obteniendo resultados favorables, se los iré comunicando con el interés y entusiasmo que la cosa me inspira y yo particularmente trabajaré cuanto pueda, pues no me duelen prendas cuando del sublime Maestro se trata.

Con este motivo quedo de $\mathrm{Vd}$. affmo., amigo, que simpatiza en un todo con sus ideales y S.S.

Q.B.S.M.

[Firma autógrafa de Manuel de Cendra]

7

Madrid, 9 de Mayo de 1912

Sr. D. Joaquín Pena

Barcelona

Mi distinguido amigo:

Del contenido de su carta 17 del pasado di cuenta oficialmente el día 5 del actual en Junta que celebramos la Directiva, acordando en su consecuencia aceptar en principio las fechas 26 y 27 del presente mes para ir al Monasterio de Piedra a reunirnos con $V d s$.

Si ahora no de una manera segura, una semana antes, o sea dentro de unos 10 días aproximadamente, escribiremos a $\mathrm{Vd}$. asegurándole nuestra idea, lo que no podemos hacer hoy, por no saber todavía si el Vicepresidente, Sr. Arín, esos días podrá dedicarlos al viaje en cuestión.

De todos modos, si en las citadas fechas no podemos realizar el viaje, todo sería cuestión de una semana de retraso.

Por nuestro querido compañero Viñas habrá Vd. sabido la buenísima acogida que S. M. el Rey nos dispensó, alentándonos en la hermosa obra que proyectamos.

De palabra cambiaremos impresiones sobre este asunto.

Hasta mi próxima se despide su atto. S S. que en nombre de los compañeros de Junta

L.B.L.M.

[Firma autógrafa de Manuel de Cendra] 
Madrid, 20 de mayo de 1912

Sr. Don Joaquín Pena

Barcelona

Muy distinguido Sr. mío y amigo:

En contestación a su atenta fecha 16 del actual, tengo la contrariedad de manifestar a $\mathrm{Vd}$. que en la reunión que ayer noche tuvimos los señores que forman la Junta Directiva de esta Asociación, para tratar única y exclusivamente del proyectado viaje a Piedra, se vio la imposibilidad en que nos hallamos de concurrir a dicho Monasterio los días 26 y 27 del mes actual, fecha que ustedes proponen y que nosotros habíamos aceptado en principio, siendo esta imposibilidad fundada en los motivos siguientes.

La comisión que se nombró desde el primer momento para ir a reunirse con Vds. está formada por el Vicepresidente, Sr. Arín, yo como Secretario, el Sr. Manrique de Lara, bibliotecario, el Sr. Ramos, tesorero, los vocales Srs. Marañón, Borrell, Saco del Valle y Gaisse; el arquitecto La Roca, varios individuos de los más entusiastas entre los socios y tres periodistas. Pues bien, el señor Arín, que presidirá la comisión precisamente el día 26, es la fecha de su entrada o recepción en la Real Academia de San Fernando, acontecimiento que sus amigos y nosotros sus compañeros de Junta, vamos a celebrar mucho; el Sr. Manrique, los días 26 y 27 tiene un asunto de gran interés que precisa su presencia en la Corte; el Sr. Saco del Valle unos conciertos en esos días festivos bajo su dirección; el Sr. Borrell, médico distinguidísimo tiene esos días justamente guardia en el Hospital General y por último todos los demás deseamos asistir a la recepción académica de nuestro Vicepresidente cuya fecha hasta el sábado pasado no fijó la Real Academia.

Nuestra contrariedad es grande, pues todos tenemos gran empeño en acudir a la reunión tan acertadamente pensada y dispuesta. Proponemos a Vds. en su consecuencia los días 2 y 3, 9 y 10, o 16 y 17 de junio próximo, pues son estos días domingos y lunes respectivamente, saliendo todos de una y otra capital el sábado antes por la tarde, para llegar por la noche a Piedra. Vds. tienen la palabra.

Un cariñoso saludo a todos los demás compañeros de Directiva en nombre de los nuestros y en espera de su contestación,

quedo como siempre de $\mathrm{Vd}$. affmo. amigo,

S.S.Q.E.S.M.

[Firma autógrafa de Manuel de Cendra] 
9

Madrid, 30 de Mayo de 1912

Sr. Don Joaquín Pena

Barcelona

Mi distinguido amigo:

En la Junta que celebramos anoche la Directiva, di cuenta del contenido de su carta 28 del actual, que acababa de recibir horas antes y se acordó poner a Vds. un pequeño cambio de fechas y es el siguiente: En lugar de estar fuera los días 9 y 10, que son Domingo y Lunes, pasar los días 8 y 9 en Piedra que son Sábado y Domingo, pues el día 10 tiene precisión el Sr. Arín de estar en Madrid.

Tenga $\mathrm{Vd}$. la bondad de contestarme a vuelta de correo si están $\mathrm{Vds}$. conformes, y en este caso queda determinado de una manera concreta que saldremos cada comisión de su capital respectiva el Viernes día 7 por la noche.

También este aplazamiento nos ha costado algunas bajas muy lamentables en nuestra Comisión, pues el Sr. Saco del Valle no podrá concurrir al viaje y tal vez tampoco pueda formar parte de dicha comisión nuestro compañero el Sr. Manrique de Lara.

Veremos de sustituir a estos Srs. animando a Félix Borrell y a algún otro de sus mismos entusiasmos.

En espera de su pronta contestación y agradeciéndole mucho las amables manifestaciones que al final de su atta., me dirige cuyos deseos recíprocos de conocer a Vd. son en mí grandísimos, queda de Vd. affmo. S. S.

Q.L.B.S.M.

[Firma autógrafa de Manuel de Cendra]

10 [Telefonema enviado por Manuel de Cendra a la AWB el 7 de junio de 1912 a las $10.50 \mathrm{~h}]$

Suspendemos viaje por causa repentina, tres enfermos, detalles correo, perdón a todos. Manuel Cendra.

11 [Telefonema enviado por Joaquim Pena a la AWM el 7 de junio de 1912 a las $13.00 \mathrm{~h}]$

Urgente.

Recibido telefonema una tarde, faltan breves horas salida tren. Imposibilitado reunir compañeros, adquirido billetes. Dispuesto todo, verificamos viaje forma convenida. Agradecemos acuda a Piedra alguno de Vds. Pena.

12 [Telegrama enviado por Manuel de Cendra, desde Madrid a Piedra, a Joaquim Pena el 7 de junio de 1912 a las 18.30 h y recibido por este último en la oficina de Alhama]

DOl10.1344/Materia2014.8.3 
Imposible acudir nadie por aumento dificultades lamentándolo de corazón nos unimos proyecto aprobando lo que Vds. acuerden en ésa. Cendra.

13 [Telegrama enviado a las $24.00 \mathrm{~h}$ por la Junta Directiva de la AWM a Joaquim Pena, probablemente en respuesta a otro telegrama enviado por este último el mismo 7 de junio, entre las $18.30 \mathrm{~h}$ y las $24.00 \mathrm{~h}$ y recibido en la oficina de Alhama]

Agradecemos atención telegrama acompañamos a Vds. pensamiento lamentando forzosa ausencia esperamos conocer impresiones. Junta Directiva.

\section{4}

Madrid, 7 de Junio de 1912

Sr. Don Joaquín Pena

Barcelona

Mi distinguido y querido amigo:

En este momento, 10 mañana, acabo de poner a $\mathrm{Vd}$. un telefonema urgente, anunciándole que por motivos de salud tenemos que suspender la excursión a Piedra que debíamos emprender esta noche.

Si una hora antes de la citada en que le he dirigido el despacho se hubiese decidido la suspensión, una hora antes le hubiese avisado, pero a las nueve y media de la mañana he recibido dos cartas, diciéndome los Srs. Arín y Manrique de Lara que no podían ir, el primero por haberse puesto su Sra. enferma esta noche y el segundo por estar en cama desde ayer, de cuyos Srs. hubiésemos prescindido, aunque con sentimiento, si la Comisión hubiese sido numerosa; pero en estos últimos días se ha ido reduciendo de tal manera, por motivos todos serios y atendibles, que sólo ayer tarde íbamos a emprender el viaje 4 Srs., y de ellos los dos que cito han sido bajas a última hora, no siendo cosa de que marchásemos después de tanto pensarlo únicamente dos comisionados.

Crea $\mathrm{Vd}$. que tengo un verdadero disgusto por todos estilos y que para que esto no vuelva a ocurrir vamos a celebrar Junta dentro de un par de días, con objeto de decidir de una manera concreta quiénes y cuándo podemos garantizar a $\mathrm{Vd}$. el viaje, poniéndonos a sus órdenes por la estorsión [extorsión] que seguramente les habremos ocasionado con aviso tan de última hora.

Como en la próxima combinación que hagamos es de esperar no ocurran tantas contrariedades, y teniendo en cuenta que todos deseamos vivamente llevar a cabo el hermoso proyecto, puedo asegurarle que pediré un sacrificio si es menester a mis compañeros, para que se lleve a cabo la excursión a todo trance.

Perdone una vez más a su affmo. amigo que desea vivamente conocerle y darle un abrazo como el que le envía, quedando suyo S.S.

Q.B.S.M.

[Firma autógrafa de Manuel de Cendra] 


\section{5}

Barcelona, 18 de junio de 1912

Sr. Don Manuel de Cendra

Mi distinguido amigo:

A nuestro regreso de Piedra encontré en casa la carta de $\mathrm{Vd}$. escrita días atrás a raíz de su telefonema anunciando la suspensión del viaje de $\mathrm{Vds}$. El contenido de aquélla me enteró de lo acaecido en el seno de esa comisión y me hago cargo de ello perfectamente, pues por experiencia sé lo que cuesta mover a la gente. Por tanto me limito a desear el restablecimiento de los enfermos y a deplorar la ausencia de $\checkmark d s$. que por una parte nos priva del gusto de conocerlos personalmente y por otra vino a hacer infructuoso nuestro viaje o por lo menos a retardar su resultado práctico. Aunque tardía y por las ocupaciones que sobre mí han pesado desde el regreso, debo a $\mathrm{Vd}$. una explicación de los motivos que nos decidieron a emprenderla. Por una parte, a la hora en que recibí el aviso, faltando ya pocas para la marcha, era del todo imposible llegar a reunir a mis compañeros para resolver lo procedente. Además, la suspensión nos representaba la pérdida de los billetes, que había ya adquirido el tesorero. $Y$, por si eso no bastara, uno de nuestros compañeros, el pintor escenógrafo Sr. Junyent, no podía demorar por más tiempo su salida para el extranjero, que venía ya aplazando desde el principio de mes, por acompañarnos. Hay que tener en cuenta que al propio compañero le habíamos causado ya otra extorsión con el aplazamiento del mes de Mayo, pues antes de tener noticia del mismo, regresó ex-profeso de Mallorca donde, de lo contrario, hubiese permanecido hasta fin del mes pasado y por sus conocimientos técnicos en la materia era el amigo Junyent insustituible, pues ha recorrido por dentro los principales teatros de Alemania y conmigo visitó el propio escenario de Bayreuth, donde recogimos datos para aprovecharlos en su día. Con estos antecedentes espero que se harán cargo de la precisión en que nos vimos de emprender el viaje y no lo consideraran una descortesía de nuestra parte. Por lo contrario, abrigábamos todavía la esperanza de que alguno de $V d s$. se animaría a venir al conocer nuestro telegrama de salida.

La excursión realizose con toda felicidad y las impresiones recibidas superaron a nuestros mayores optimismos. El lugar que había sido escogido in mente para la realización de nuestro sueño, sólo por la fama de que goza Piedra, es realmente ideal, incomparable, y reúne todas las condiciones requeridas al objeto nuestro. Mi pobre pluma resulta impotente para hacer a $V d s$. una descripción de cuanto vimos y sentimos, cuanto gozamos y cuantos planes proyectamos. Pero nuestro compañero de excursión, el redactor crítico de arte y de La Publicidad, Sr. Jori, ha sabido expresar a maravilla en dicho periódico la quintaesencia de las impresiones recibidas, de los detalles del proyecto, de los trabajos verificados y del estado actual del asunto. Remitimos por paquete postal una partida de ejemplares de ese artículo para que se sirva distribuirlo entre la Junta Directiva y demás interesados en el asunto, haciéndoles constar que todos los expedicionarios suscribimos gustosos como eco fiel de nuestro pensamiento, salvando por lo que atañe a mí particularmente las desmesuradas frases encomiásticas que me dedica, hijas más bien de una entrañable amistad que nos une, que mis méritos reales y positivos. 
Tocante a la parte artística del proyecto, creo preciso añadir otra cosa a lo expuesto por el amigo Jori. Recorrimos toda la posesión, buscamos y encontramos por fin el sitio ideal para nuestro objetivo, lejos del rumor de las cascadas, tomamos las oportunas medidas para el escenario, orquesta y espacio del espectador, planeamos la forma de realizar los trabajos; en una palabra, creo que dejamos resueltos in mente los detalles primordiales, de la misma manera que tenemos calculados los elementos artísticos para las representaciones, todo lo cual expondremos a $V d s$. en el momento que hubiere de entrarse en la parte práctica del asunto.

Por otra parte dejamos sellada con la familia Muntadas, que afortunadamente se encontraba allí, casi en su totalidad, la más cordial alianza en beneficio mutuo. Uno de los hijos, D. Ramón, representando a su anciano padre y a sus hermanos, nos acompañó cortésmente dándonos toda clase de facilidades y poniendo en adelante a nuestra disposición la finca, asegurándonos que no habría por parte de los propietarios entorpecimientos ni intempestiva pretensión que pudieran malograrlo.

Sólo un punto queda pues a resolver pero ésa es precisamente la cuestión capital: la parte económica de la empresa. Conocida ya la posibilidad de su realización artística, todo estriba en saber si contaríamos con los medios suficientes para llevarla a cabo. Mas eso no podíamos resolverlo allí por nosotros mismos, sino que nos era absolutamente necesaria la presencia de $V d s$. a fin de cambiar opiniones sobre los tanteos verificados y sobre la posibilidad de levantar el capital indispensable. Por lo que a nosotros atañe, no he de hacer sino ratificarme en cuanto exponía bien claramente en mi carta de Febrero acompañando el proyecto de base. Aquí puede hacerse algo, pero precisa la participación principalísima y, sobre todo, la iniciativa de Vds. para convencer a nuestra gente. A Vds. toca, pues, exponer su opinión sobre el particular, teniendo en cuenta todos los resortes que en ésa puedan tocarse, oficiales y particulares, con esperanzas de éxito. Indudablemente, lo más práctico es lanzar cuanto antes una emisión de acciones y trabajar con alma y vida por cubrirla lo antes posible. Para saber la cantidad que hay que pedir, precisa un presupuesto aproximado de gastos y esto no puede deducirse de nuestra visita aislada a Piedra, sin temor a error gravísimo. Es más, ni aun en el supuesto de habernos reunido allí ambas comisiones acompañadas del personal técnico correspondiente, creo que hubiera sido posible establecer aquél de una manera exacta, debido a mil circunstancias imprevistas, entre ellas la cuantía del material escénico, que forzosamente hay que pedir al extranjero, para lo que es preciso ante todo pedir precios o, mejor aún, Ilamar a un perito en la materia para que los dé sobre el terreno. Lo único que nosotros podemos comunicar a $V$ ds. es una opinión hija más bien de la impresión personal que basada en un cálculo real y efectivo, en el entendido de que sólo han de tenerla Vds. a beneficio de inventario. Resumiéndola, para abreviar, dividimos el costo total prescindiendo de momento del gasto material de cada representación en dos conceptos:

$1 .{ }^{a}$ ) construcción del teatro en condiciones de ser explotado en años sucesivos, única manera de asegurar a los accionistas un negocio que de otra suerte es forzosamente ruinoso; 
2. ${ }^{a}$ ) habilitación del Monasterio de Piedra para hospedar el número conveniente de personas.

En cuanto al primer extremo, hemos deducido que la sala completamente cerrada costaría menos de lo que temimos, debido a las condiciones naturales del sitio designado y a la facilidad de proporcionarnos la misma finca toda la piedra necesaria, si bien el principal elemento de construcción debiera ser la madera y parte de hierro. El coste del escenario sería fácil de [calcular] por lo que se refiere a esos elementos, pero más difícil respecto a la complicada maquinaria, para lo que me atengo a lo que he expuesto más arriba.

Por lo que hace al segundo extremo, el hospedaje en Piedra, recorrimos el Monasterio y sacamos la convicción de que si hoy no está habilitado más que para un par de centenares de personas, hay allí cabida suficiente para muchísimos centenares más, verificando las obras necesarias. Hay local en grande por habilitar, y todo es cuestión de tabiques, no de paredes ni techos, calculando en $2.000 \mathrm{el}$ número de espectadores. Así creemos que cogerían en el Monasterio si no todos, que es un imposible, por lo menos unas dos terceras partes, y para el resto se puede contar con los grandes establecimientos de Alhama, distante hoy sólo 3/4 de hora del Monasterio, merced a un buen servicio de automóviles ya establecido. Por lo tanto, con un buen maestro de obras y un contratista de muebles necesario, podría fijarse con bastante exactitud la cifra total con respecto de este punto.

Como consecuencia de todo lo expuesto y sólo para dar a Vds. una cifra hipotética (después de repetir que no nos declaramos competentes en la parte técnica) venimos a suponer que el capital inicial debiera ser por lo menos de un millón de pesetas para ampliarlo luego si fuera preciso.

La cifra es respetable, no hay duda, y aun así, no respondemos de quedarnos cortos, poco o mucho, pero también consideramos que en más o menos tiempo puede llegar a ser un negocio. La cuestión de la manera de lanzarlo es, en un principio, la manera de hacer luego la reclama, sobre todo en el extranjero, y por fin, de una excelente administración y una inteligente dirección artística.

Si la iniciativa privada no basta para ello, es cuestión de convertirlo en obra nacional, abriendo suscripciones en todas las grandes capitales y reclamando el apoyo oficial del Rey y del Estado, Diputaciones y Ayuntamientos más interesados y Corporaciones de cultura.

Del extranjero me escriben ya pidiendo detalles y no hay duda que la empresa puede llegar a tener una resonancia mundial que nos permita verificar un número de representaciones superior a los cálculos más optimistas.

Ahí tiene Vd., amigo Cendra, borroneada a vuela pluma, mi impresión que es la de mis compañeros. Ahora tienen Vds. la palabra. La capital de España es la que debe gritar iadelante! o tocar a retirada. Nosotros estamos siempre dispuestos a formar en las avanzadas.

Como que no nos queda más tiempo que perder, yo ruego a $V d s$. que tomen una resolución definitiva sobre el particular a la mayor brevedad posible antes de que se inicie la desbandada del verano. Reúnanse $V$ ds. en seguida, cambien impresiones sobre lo que llevamos expuesto, Iléguense personalmente a Piedra, que no está tan lejos de ésa, rectifiquen nuestros equivocados puntos de vista, expóngan- 
nos sus impresiones y razonamientos y borroneen las bases definitivas de la nueva sociedad artística o, en último término, desengáñennos $V$ ds. de una vez, para abandonar en la región de los sueños irrealizables una idea que hoy ya empieza a trascender demasiado al público.

Próxima nuestra Asociación a verificar la Junta General reglamentaria, seríanos muy conveniente saber a qué atenernos en este importante asunto, para exponerlo en la forma que mejor proceda.

Sírvase transmitir en mi nombre y en el de mis compañeros nuestro más afectuoso saludo a todos los individuos de esa digna Junta Directiva y a cuantos comparten nuestro ideal, y a $\mathrm{Vd}$. particularmente le agradecemos sus constantes desvelos en el asunto.

Su affmo. amigo S.S.

Q.B.S.M.

[Joaquim Pena]

16

Madrid, 25 de junio de 1912

Sr. D. Joaquín Pena

Barcelona

Mi distinguido y querido amigo:

A su extensa carta 18 del actual, vamos a contestar oficialmente con la atención que el asunto requiere, tan pronto nos reunamos por segunda vez con este objeto puesto que ya hemos tenido la Directiva una primera reunión para tratar de los puntos principales que debemos decirles, emitiendo claramente nuestro criterio como Vds. desean.

Con toda seguridad, del sábado al domingo próximos recibirá Vd., la extensa carta que le anuncio.

Con este motivo, queda de Vd. affmo. amigo S.S.

Q.B.S.M.

[Firma autógrafa de Manuel de Cendra]

17

Madrid, 1 de julio 1912

Sr. D. Joaquín Pena

Barcelona

Mi distinguido y querido amigo:

Ayer noche nos reunimos por segunda vez la Junta Directiva de esta Asociación para tratar ampliamente, con el interés que nos inspira el proyecto de representaciones de Parsifal en el Monasterio de Piedra, y con objeto de poder contes- 
tar a las preguntas y razonadas proposiciones que en nombre de la Wagneriana de Barcelona nos formula $\mathrm{Vd}$. en su atta. carta, fecha 18 del pasado.

Nuestra actitud desde el primer momento, desde su primera carta iniciadora de esta hermosa idea, no ha podido ser más entusiasta por entender que una iniciativa de la naturaleza de la propuesta merecía ser acogida y secundada con tanto mayor interés, cuanto que en ella se trata de glorificar al inmortal maestro, cuya obra nos llena a todos de admiración profunda.

Desde el primer momento, repito, sentimos un gran deseo de llevar a la práctica el soñado proyecto.

Lo mucho que nos hemos ocupado durante este tiempo propagando entre nuestros compañeros de Asociación la idea y más tarde la entrevista que con este objeto celebramos con su S. M. el Rey son señales evidentes de nuestro amor a este asunto y de nuestra actitud decidida en apoyo del mismo.

Individualmente todos los Señores que constituimos la Directiva lo hemos estudiado también; hemos hecho gestiones aisladas con personas influyentes, obteniendo de todos la misma respuesta al problema; ésta es, calificar de grandioso pensamiento y digno proyecto de unas agrupaciones de la naturaleza de las nuestras, pero (y este pero es desconsolador), a juicio de los consultados, irrealizable por la inmensa dificultad de encontrar dinero para la empresa, en un país donde la afición al arte se halla en las más modestas esferas y en donde nosotros, en nuestra Asociación, no hemos podido conseguir aumentar a cinco, la cuota mensual, de dos pesetas que pagan nuestros socios. Ahora mismo, en Junta General, celebrada el día 20 del pasado Junio, no se ha logrado, y triste es confesarlo, que los Socios satisfagan una peseta mensual como suscripción obligatoria a una importante «Revista Wagneriana» que proyecta fundar esta Asociación y en cuyas páginas se ha de ir dando metódicamente la traducción castellana de los poemas y demás obras literarias de Wagner.

En Madrid, el capital y el arte andan siempre a cachetes; aquí no existe, y es una necesidad cada día mayor un salón de conciertos, ni modesto siquiera, y en fin, nosotros que tenemos también en estudio el edificar un templo al arte musical; para poder realizar tan sensato proyecto, hemos de presentarlo como un negocio, es decir, edificando la Sala de Conciertos en un patio de una gran casa de vecindad, cuyas tiendas, almacenes y demás dependencias mercantiles aseguren al escamado accionista un interés a su dinero, único medio de conseguir éste.

¿Cómo puede presentarse el proyecto de Piedra dándole caracteres financieros? Nosotros entendemos que es imposible, que no hay manera de garantizar ese millón de pesetas que $V d s$. con muy acertado cálculo estiman necesario, y desde el momento en que sólidamente no se garantice aquél y se marque un interés seguro a las acciones no se obtendrá en Madrid ni la más modesta cifra para el proyecto, que si a los wagnerianos nos hace meditar, qué no hará a los que todo lo ven con la desconfianza natural de un riesgo posible.

Yo he tratado personalmente este asunto con algunos políticos de mi amistad y sobre todo con uno que por su carácter de entusiasta wagneriano y ferviente admirador del arte en general no me era sospechoso de criterio respecto al asunto que le consultaba. Le expuse nuestra idea respecto a solicitar el apoyo del Gobier- 
no y de otras esferas oficiales y me contestó que, conocedor de nuestra política (a que pertenece) y del elemento oficial, niega rotundamente la posibilidad del pretendido apoyo por no haber precedentes respecto subenciones [subvenciones] análogas. Añadió que no otorgándose casi nunca a las manifestaciones de arte nacional, con mayor dificultad, se puede lograr en este caso, pues en el informe que emitieran, la Academia de San Fernando y el Conservatorio, seguramente se negaría la protección con cierta lógica en este caso, puesto que en un país donde no se ampara el arte musical patrio menos se ha de subencionar [subvencionar] al extranjero.

Nosotros no quisiéramos, nos duele con toda el alma, hablarles de esta forma, pero la gran simpatía que por Vds. sentimos y el respecto [respeto] que el hermoso proyecto nos inspira, oblíganos a responderles con el corazón en la mano, sin reservas, con la verdad por triste que ésta sea y que todos los de aquí unánimemente sentimos.

Con claridad debemos decirles que serán estériles cuantos esfuerzos en Madrid se realicen; la opinión es contraria al proyecto por la enorme cifra que a él hay que aportar, la que sólo un capitalista amante de nuestra causa puede ofrecer solucionando de este modo el difícil problema monetario que a nuestro juicio se presenta.

Pero como nuestra actitud no puede ser, no debe ser, sospechosa para Vds. y podría ocasionar el que desistieran del proyecto; si a pesar de nuestras manifestaciones estiman que deben llevarse adelante, nosotros les ayudaremos intentando la emisión de acciones en Madrid en igual forma que $V d s$. realicen la de esa capital.

Queda bien entendido que esta Junta Directiva no pretende echarse fuera en el asunto, sino responder con claridad y con conocimiento de lo que aquí se piensa; pero siempre adicta como lo estará también si al desistir $V d s$. de este proyecto quieren que entablemos negociaciones juntos para celebrar en el próximo mes de Mayo y con iguales elementos unos festivales en conmemoración del glorioso centenario que se aproxima, celebrando cada Asociación en su respectiva capital las representaciones o Veladas que ambas partes convengan y para las que con más facilidad estando unidos pueden contratarse elementos españoles o extranjeros que realicen su labor artística con más economía al ser llamados por ambas entidades.

Estamos pronto a secundar lo que Vds. propongan y lamentando que el contenido de la presente no sea lo grato que nuestra adhesión a sus ideales quisiera, queda de Vds. y especialmente suyo, su más affmo. y devoto amigo, S.S.

Q.B.S.M.

Por la Junta Directiva

[Firma autógrafa de Manuel de Cendra] 